\title{
Magneto-mechanical Effect on the Magnetic Properties and Microstructures in Nanocrystalline Fe-Cu-Nb-Si-B Alloys
}

\author{
TAYLAN GUNES
}

\begin{abstract}
In the current study magnetic, magneto-optical, and morphologic and structural properties of the amorphous $\mathrm{Fe}_{82} \mathrm{Cu}_{1} \mathrm{Nb}_{3.5} \mathrm{Si}_{5.5} \mathrm{~B}_{8}$ (NC1) and $\mathrm{Fe}_{77.5} \mathrm{Cu}_{1.5} \mathrm{Nb}_{5} \mathrm{Si}_{7} \mathrm{~B}_{9}$ (NC2) alloys were investigated at elevated temperatures with and without tensile loading. Kinetic nanocrystallization temperatures of certain ribbons were properly determined at the range of $500{ }^{\circ} \mathrm{C}$ to $555^{\circ} \mathrm{C}$. Furthermore, an unusual method was preferred to identify the tensile loading conditions regarding relative permeability values in the as-cast (AC) state to specify stress annealing conditions. The present properties yielded an ultrafine-grain structure correlated with the literature results. AC-state, tensile-loaded, heat-treated, and stress-annealed specimens were separately examined to ensure their improvement in terms of magnetic properties and structures as well as magnetic domains. Besides, variations of induced anisotropy with respect to tensile loading and coercivity made the evaluation of the magnetic microstructures possible. In addition, the observed magnetic domains contribute further knowledge to the available magnetic microstructures. Good correlation between the determined magnetic properties and observed microstructures was found. Eventually, the optimum nanocrystallization requirements of $\mathrm{NC} 1$ and $\mathrm{NC} 2$ could be determined as $70 \mathrm{MPa}+535^{\circ} \mathrm{C}$ and $120 \mathrm{MPa}+555^{\circ} \mathrm{C}$, respectively. Such requirements lead to achieving transverse induced anisotropy, which also allows forming periodic alignment of transverse domains.
\end{abstract}

https://doi.org/10.1007/s11661-019-05323-9

(c) The Minerals, Metals \& Materials Society and ASM International 2019

\section{INTRODUCTION}

IN recent studies, nanocrystalline $(\mathrm{NC}) \mathrm{FeCuNbSiB}$ soft magnetic materials produced in as-cast (AC) state from the amorphous precursor by the primary crystallization of bcc Fe have been found remarkable as they have superior magnetic properties. ${ }^{[1-3]}$ To obtain the NC state, primary crystallization should be achieved via a heat treatment above the crystallization temperature. ${ }^{[4]}$ Such produced ribbons enabling efficient usage in many electronic and electromechanical circuits have been widely investigated in terms of both magnetic properties $^{[1,5-7]}$ and microstructures. ${ }^{[8-12]}$

$\mathrm{NC} \mathrm{FeCuNbSiB}$ alloys are commonly known by the lowest coercivity, $H_{\mathrm{c}}(<1 \mathrm{~A} / \mathrm{m})$, a fulfilling permeability, $\mu\left(>1 \times 10^{5}\right)$, a very low magnetostriction, $\lambda_{\mathrm{s}}$ $(<1 \mathrm{ppm})$, and a sufficient saturation polarization, $B_{\mathrm{S}}$ $(\approx 1.25 \mathrm{~T}) .^{[1,2,13]}$ Knowing the composition of $\mathrm{NC}$ alloys would be a significant source for making a

TAYLAN GUNES is with the Department of Energy Systems Engineering, Yalova University, 77100, Yalova, Turkey. Contact e-mail: taylan.gunes@yalova.edu.tr

Manuscript submitted February 20, 2019.

Article published online June 20, 2019 prediction regarding their magnetic behavior and crystallization temperature based on their $\mathrm{Fe}$ content percentage. ${ }^{[14]}$ The balance ratio of $\mathrm{Cu}$ and $\mathrm{Nb}$ would also provide approximate prior knowledge of the mean grain size of FeSi grains. ${ }^{[15,16]}$ Thus, the addition of sufficient $\mathrm{Cu}$ contributes obviously to the uniformity of grain dispersion. ${ }^{[17,18]}$ Ohnuma et al. ${ }^{[19]}$ pointed out that $\mathrm{Cu}$ clusters are closely related to bcc $\alpha$-Fe primary crystals so that their grain size directly influences the permeability of the alloy. Therefore, the relevant ratio of $\mathrm{Cu}$ and $\mathrm{Nb}$ makes it possible to obtain a uniform $\mathrm{NC}$ microstructure evaluation.

Even though Finemet, Nanoperm, and Vitroperm are prominent and commonly known members of the class of $\mathrm{NC} \mathrm{FeCuSiBNb}(\mathrm{Zr}, \mathrm{P})$ alloys, the ratio of elemental percentages in their composition varies depending on the area of usage or the customer demands. For instance, magnetic cores of several inductive components such as chokes or transformers may lead to various desired magnetic properties, e.g., higher values of permeability $(\mu)$, saturation induction $\left(B_{\mathrm{s}}\right)$, and lower core loss $\left(H_{\mathrm{c}}\right)$. No matter what the usage purpose of $\mathrm{NC}$ soft magnetic materials, one of the most significant requirements is generally a quite low $(<1 \mathrm{ppm})$ or vanishing $(\approx 0)$ magnetostriction $\left(\lambda_{\mathrm{s}}\right)$, which reduces magneto-elastic anisotropies $\left(K_{\sigma}\right){ }^{[20-22]}$ The key to the 
understanding of a higher permeability level of NC alloys is the easy rotation of magnetization and easy domain wall motion, which originate from low magnetocrystalline anisotropy $(K)$ and low $\lambda_{\mathrm{s}} .{ }^{[23]}$ Such microstructural refinement after some mechanical and or thermal treatments have been implemented would reveal superior soft magnetic properties, such as average grain size $(D)$, lower $H_{\mathrm{c}}$, high $B_{\mathrm{s}}$, and small pinning forces. ${ }^{[5]}$ On the other hand, all these different requirements necessarily restrain the selection of the alloy. Kuhnt et al. ${ }^{[21]}$ reported that the $\lambda_{\mathrm{s}}$ of the NC ribbon having $\mathrm{Fe}$ content of around 85 pct was measured as large as $14 \mathrm{ppm}$, while its saturation polarization was increased up to $1.86 \mathrm{~T}$, and the grain size was about 16 to $18 \mathrm{~nm}$. Yoshizawa et al. ${ }^{[24]}$ proved that Finemet NC material indicates a $B_{\mathrm{s}}$ around $1.3 \mathrm{~T}$ and a $\lambda_{\mathrm{s}}<1 \mathrm{ppm}$.

The actual feature of NC Fe-based alloys appears during the phases formed at crystallization that should initially lead to a decrease of $\lambda_{\mathrm{s}}$ depending on the circumstances of heat treatment in the course of magneto-mechanical stress. This is the way to enable a simultaneous increase of initial permeability $\left(\mu_{\mathrm{i}}\right)$. In this sense, the balance among the volume fraction of the crystalline phase, local magnetostriction constant of $\alpha-\mathrm{FeSi}$ grains, and residual amorphous matrix plays an important role in determining the value of $\lambda_{\mathrm{s}}$ as indicated in Eq. [1]:

$$
\lambda_{\mathrm{s}} \cong v_{\mathrm{cr}} \cdot \lambda_{\mathrm{s}}^{\mathrm{FeSi}}+\left(1-v_{\mathrm{cr}}\right) \lambda_{\mathrm{s}}^{\mathrm{amrph}},
$$

where $\lambda_{\mathrm{s}}^{\mathrm{FeSi}}$ and $\lambda_{\mathrm{s}}^{\mathrm{amrph}}$. represent the local magnetostriction constants of $\alpha$-FeSi grains and residual amorphous matrix, respectively. $v_{\text {cr }}$ denotes the volume fraction of the crystalline phase. Depending on the value of $v_{\mathrm{cr}}$, positive or negative magnetostriction could be obtained considering Eq. [1]. After the nanocrystallization onset temperature has formed, $v_{\mathrm{cr}}$ in these materials should be in the range of 75 to 80 pct with a grain size of about $10 \mathrm{~nm} \cdot{ }^{[5]}$ This case also depends on the Si content of the material. Si content between 13 and 16 pct leads to the vanishing of $\lambda_{\mathrm{s}}$ as a function of annealing temperature. ${ }^{[25]}$

It is also well known that $\mathrm{NC}$ ribbons are extremely sensitive because of their glassy formation due to their $\mathrm{Si}$ and $\mathrm{B}$ content. Particularly adversities necessarily emerge during the production of the $\mathrm{NC}$ core with transverse anisotropy. ${ }^{[26]}$ In other words, magneto-mechanical effects occurring during the winding-induced bending to the $\mathrm{NC}$ ribbons obstruct obtaining a core with transverse anisotropy, ${ }^{[27]}$ which may cause the periodic alignment formation of transverse domains ${ }^{[28]}$ to the long axis. González et al. ${ }^{[29]}$ investigated magnetic behaviors of $\mathrm{NC}$ soft magnetic ribbons after proper annealing conditions were implemented under tensile stress, i.e., stress annealing. However, examination of tensile stress without annealing is so far missing in terms of magnetic properties and magnetic domain structures.

To produce the NC core with the air gap as small as possible in terms of volume, winding-induced bending tensile stress is necessarily applied to the ribbons during manufacturing. ${ }^{[27]}$ Here two processes arise: first, winding-induce bending tensile stress is applied to the AC ribbons. Then, the produced core is subjected to heat treatment with or without a magnetic field. ${ }^{[20]}$ Thus, ribbons generally become extremely brittle after they have been exposed to the heat treatment even in the range of the first crystallization temperature, which depends mainly on the composition of the ribbon for some 10 minutes. Although flash annealing performed in a few seconds would provide a smart solution for this problem, ${ }^{[30]}$ it is believed that magnetic properties are permanently developed after heat treatment of about 10 to 15 minutes. ${ }^{[5]}$ This is why the ideal solution for manufacturers is to perform restrained tensile stress on the $\mathrm{AC}$ state ribbons as long as the core is produced under ideal conditions. Subsequently, a mild heat treatment would be implemented on such cores with or without a magnetic field.

In a sense, the purpose of the current investigation is to determine the physical indication of simultaneous application of heat treatment and tensile stress. To do this, AC-state, annealed, and stress-annealed specimens were separately investigated regarding their mean grain size, saturation polarization, coercivity, induced anisotropy, permeability, and evaluation of magnetic domain structures. Schäfer ${ }^{[9]}$ indicated that all domains could be determined by stress patterns in the as-quenched state. Otherwise, unless the material was heated under the influence of a magnetic field, an induced anisotropy resulting from a random orientation would lead to a non-uniform distribution of the domain configuration that makes it difficult to distinguish. To overcome this complexity in the current study, the presence of the stress patterns in the AC state was determined using the magneto-optical Kerr effect and annihilated by relevant thermal treatments in the existence of a magneto-mechanical effect.

\section{EXPERIMENTAL PROCEDURES}

Precursor amorphous ribbons with the nominal composition of $\mathrm{Fe}_{82} \mathrm{Cu}_{1} \mathrm{Nb}_{3.5} \mathrm{Si}_{5.5} \mathrm{~B}_{8}$ (NC1) and $\mathrm{Fe}_{77.5} \mathrm{Cu}_{1.5} \mathrm{Nb}_{5} \mathrm{Si}_{7} \mathrm{~B}_{9}$ (NC2) were prepared by induction melting under a high-purity argon atmosphere. The thicknesses of produced as-spun ribbons, $\mathrm{NCl}$ and $\mathrm{NC} 2$, were found to be $\sim 30$ and $\sim 20 \mu \mathrm{m}$, respectively. They were quantitatively confirmed by both scanning electron microscope (SEM) micrograph and spiral micrometer. Quasi-static hysteresis curves were measured in a solenoid frame with a pick-up coil and driving coils wound around the ribbon as sketched in Reference 31 with a tensile force of 1 to $150 \mathrm{MPa}$. Besides, saturation density was also confirmed by a vibrating sample magnetometer with a maximum applied field of $15 \mathrm{kA} / \mathrm{m}$. The alloys in the AC state were isothermally evaluated by differential scanning calorimetry (DSC, Netzsch 404C) at a heating rate of $0.67{ }^{\circ} \mathrm{C} / \mathrm{s}$ under a nitrogen flow. Accordingly, for $\mathrm{NC} 1$ and $\mathrm{NC} 2$, primary crystallization temperatures (first peak) were obtained as $535{ }^{\circ} \mathrm{C}$ and $555^{\circ} \mathrm{C}$, respectively. Then, in accordance with the DSC analyses, specimens were subjected to heat treatment in the absence of a magnetic field at various temperatures between the beginning of the first 
crystallization temperature $\left(T_{\mathrm{x} 1}\right)$ and the peak points for 60 minutes in a furnace with $\mathrm{Ar}$ atmosphere and subsequently quenched in water at room temperature. The microstructures of the $\mathrm{AC}$ and annealed ribbons were characterized by X-ray diffraction (XRD, Rigaku $\mathrm{D} / \mathrm{Max}-\mathrm{B})$ by using monochromated Mo $\mathrm{K} \alpha$ radiation. Mean grain size dimensions of the nanocrystals were calculated using the Scherrer equation from the full width at half maximum (FWHM) for the bcc (220) reflection peak. The formation and microstructure of Fe-based amorphous and NC ribbons were morphologically observed by SEM (Inspect S50). Additionally, the ratio of element abundance between surfaces and bulk was checked by electron dispersive spectroscopy (EDS, Octane Prime). Depending on the annealing and tensile loading conditions, strongly induced anisotropies, i.e., $K_{\mathrm{u}}$ around $60 \mathrm{~J} / \mathrm{m}^{3}$ (NC1) and $145 \mathrm{~J} / \mathrm{m}^{3}$ (NC2), were measured and checked particularly in relation to significant magnetic properties, such as $H_{\mathrm{c}}$ and mean grain size. The magnetic domain structure was properly observed by Kerr microscopy with either longitudinal/transversal or polar sensitivities because the anisotropy axes randomly vary their orientation, which is called random anisotropy. Hence, sensitivity preferred as perpendicular to the domain patterns allowed displaying the evaluation processes of magnetic microstructures with respect to external treatments. Frequency-independent quasi-static domain images were observed during the whole investigation.

\section{RESULTS AND DISCUSSIONS}

\section{A. Magneto-mechanical Effect Without Annealing}

Quasi-static hysteresis loops (Figure 1) resulting from progressively applied tensile stresses in the range of 17 to $150 \mathrm{MPa}$ indicate that ribbon in the $\mathrm{AC}$ state has a positive magnetostriction. As the relation between saturation magnetostriction $\left(\lambda_{\mathrm{s}}\right)$ and relative permeability $\left(\mu_{\mathrm{r}}\right)$ is well understood, their $\mu_{\mathrm{r}}$ values were compared as a function of magnetic induction measurement (Figure 1(c)). It is seen that $\mu_{\mathrm{r}}$ values of the ribbon in the AC state show a remarkable increasing trend. However, the rise was somehow stopped after $70 \mathrm{MPa}$. The reason for this peculiarity may originate from the $\lambda_{\mathrm{s}}$ value beginning to rise again. While the same conditions with $\mathrm{NC} 1$ were also valid for $\mathrm{NC} 2$, the $\mu_{\mathrm{r}}$ value of the specimen maintained its increment (Figure 2) up to the tensile force of $120 \mathrm{MPa}$, which is the threshold limit for breaking off the ribbon. Accordingly, $\mathrm{NC} 2$ in the $\mathrm{AC}$ state indicated a more uniform structure than that of NC1 in terms of an increment trend of $\mu_{\mathrm{r}}$. Nevertheless, the maximum permeability $\left(\mu_{\max }\right)$ value of the $\mathrm{NC} 1$ ribbon was measured as higher than 10 pct more than that of $\mathrm{NC} 2$.

Figures 3(a) and (b) are given to compare the characteristics of $B_{\mathrm{r} /} B_{\mathrm{s}}$ and $H_{\mathrm{c}}$ as a function of tensile stress for $\mathrm{NC} 1$ and $\mathrm{NC} 2$ to estimate the induced microstructural influence of the applied tensile stress. Particularly after $70 \mathrm{MPa}$, changes in the values of both $B_{\mathrm{r}} / B_{\mathrm{s}}$ and $H_{\mathrm{c}}$ imply that this tensile force should be approved as the threshold for $\mathrm{NC1}$. One of the most significant parameters for the formation of uniform NC2 might be its thickness (about $20 \mu \mathrm{m}$ ) and more brittle (glassy) structure, which originates from the $\mathrm{Si}+\mathrm{B}$ content, which is as much as approximately 20 pct more with respect to $\mathrm{NC1}$. Eventually, based on the primary magnetic properties of the $\mathrm{AC}$ state, the requirement of an expected glass-forming ability could be enhanced with NC2. However, it should be noted that it is hard to consistently maintain such magnetic properties after rounding up the core. A mild heat treatment is essential to make such properties permanent. Therefore, exothermic characterization (DSC analysis) is necessarily carried out for each ribbon.

\section{B. Microstructural Analyses}

Results of DSC analyses are illustrated in Figure 4; these were performed to determine the primary and secondary crystallization temperatures of the ribbons. Thus, the kinetic primary crystallization temperature of $\mathrm{NCl}\left(\mathrm{Fe}_{82} \mathrm{Cu}_{1} \mathrm{Nb}_{3.5} \mathrm{Si}_{5.5} \mathrm{~B}_{8}\right)$ and $\mathrm{NC} 2\left(\mathrm{Fe}_{77.5} \mathrm{Cu}_{1.5} \mathrm{Nb}_{5}\right.$ $\mathrm{Si}_{7} \mathrm{~B}_{9}$ ) was found at around $535^{\circ} \mathrm{C}$ and $555^{\circ} \mathrm{C}$, respectively. Thereby, the ideal crystallization temperature was basically searched for in the range of $490{ }^{\circ} \mathrm{C}$ to $535^{\circ} \mathrm{C}$ for $\mathrm{NC1}$ while it was relatively lower compared with that of $\mathrm{NC} 2$, which was between $520^{\circ} \mathrm{C}$ and $555^{\circ} \mathrm{C}$ for $\mathrm{NC} 2$. Hence, the enthalpy $(\Delta H)$ released during isothermal crystallization is the quantitative indicator of the difference caused by their crystallographic structure. However, the difference between the primary and secondary peaks was similarly found at $140{ }^{\circ} \mathrm{C}$ for both specimens, in accordance with a previous study. ${ }^{[32]}$

This situation is supported by XRD studies of the ribbon in the AC state, annealed under the Ar atmosphere and influence of tensile stress (Figure 5). Here, the evolvement of the diffraction patterns during the nanocrystallization process can be explicitly seen. These broadened reflections denote the formation of large volume fractions of $\mathrm{DO}_{3}$-type ordered nanocrystals of $\alpha-\mathrm{Fe}(\mathrm{Si})$ solid solution.

The new formations after only thermal and thermal together with magneto-mechanical treatments are evidence of the decreased grain size. The intensity of the diffraction peak may lead to predicting the crystallization volume fraction of the certain NC alloy with respect to its counterparts. ${ }^{[33]}$ Note that all XRD analyses were performed on the free surface of the ribbons. According to the intensity peaks of the AC state for both ribbons, crystallization was more or less formed toward the free-surface, even if the amorphous matrix was still dominant. This structure shows that the in-plane crystalline texture was formed during casting in the direction of wheel rotation.

To ensure this, a corresponding cross-sectional micrograph was observed by SEM, as shown in Figure 6. Here, the micrograph spots indicate the specimens of AC state and of the heat-treated one for both compositions. The existence of the veined structures in the AC state of $\mathrm{NC1}$ and $\mathrm{NC} 2$ is clearly observed here, while these veined structures from the wheel side to the free side are much more intensive in $\mathrm{NC} 1$ than in $\mathrm{NC} 2$ in 


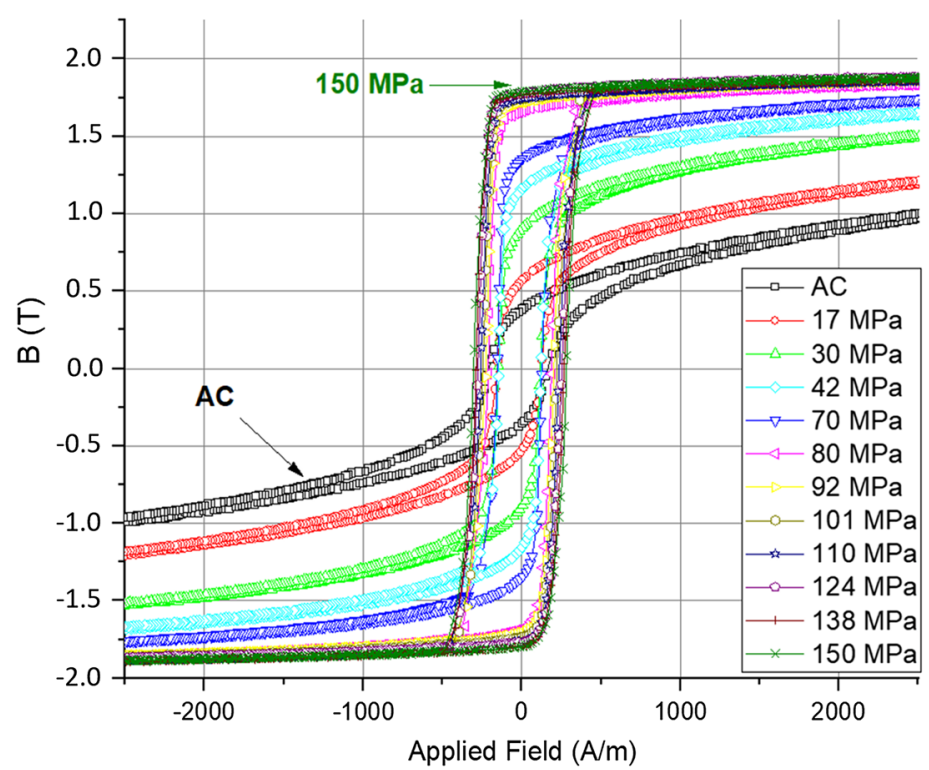

(a)

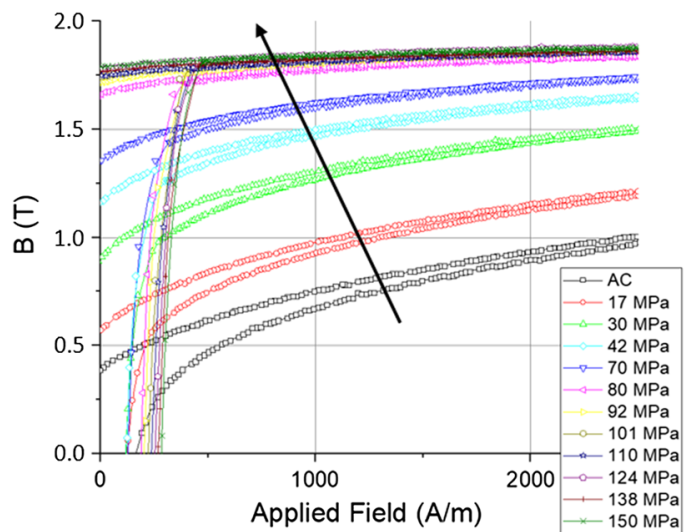

(b)

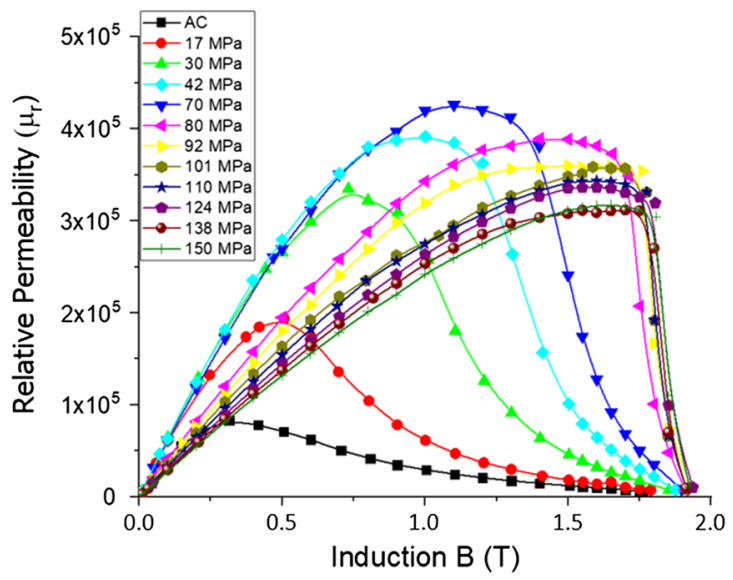

(c)

Fig. 1-Effect of tensile loading in the AC state of $\mathrm{NC1}$ : $(a)$ ascending full hysteresis curves, $(b)$ first quadrant of the curves, and $(c)$ variation of relative permeability values as a function of induction.

terms of their volume. Another significant output is that dispersion of the veined structures was found quite different in the two micrographs (AC state), even though the wheel speeds during both casting processes were held equivalent. $^{16]}$ A similar fractured morphology was defined as the ductile tensile fracture surface in amorphous alloy by Figueroa et al. ${ }^{[15]}$ Crystallization growth after mild heat treatment indicates, however, that the depletion of metalloids on the surface region could be enhanced during heat treatment. Especially heat-treated NC2 showed much more uniform crystallization than that of $\mathrm{NC1}$ between the wheel and free sides. This is because the thickness of the $\mathrm{NC} 2$ ribbon plays a decisive role in the course of formation of a highly $\mathrm{NC}$ state.

\section{Magnetic Properties}

Figures 7(a) and (b) presents the initial magnetization loops with inset full hysteresis curves taken before and after external treatments (mechanic/thermal/thermal + mechanic) for $\mathrm{NC1}$ and $\mathrm{NC} 2$. In light of the data obtained from $\mathrm{NCl}$ at $70 \mathrm{MPa}$ without heat treatment (Figure 1) and its DSC analyses (Figure 4), the specimen was exposed to both heat treatment of
$535{ }^{\circ} \mathrm{C}$ inside the furnace and heat treatment of $535^{\circ} \mathrm{C}$ under the influence of tensile stress as great as $70 \mathrm{MPa}$. Such conditions were also implemented for the NC2 under similar circumstances, i.e., heat treatment and tensile force were preferred as $555^{\circ} \mathrm{C}$ and $120 \mathrm{MPa}$, respectively.

Hysteresis loops taken from both specimens indicate that heat treatment under the influence of moderate tensile forces expectedly improves the magnetic capability of NC soft magnetic material regardless of its composition. It is also noted that tensile stress should be consistently held at the same value as long as heating and cooling would be subsequently activated until reaching room temperature. Figure 7 shows that the gradient of magnetization loops for each case is progressively changed by switching on either stress loading or annealing or stress annealing. This also means that the anisotropy field developed as long as external treatments were subsequently implemented. It is also established that the uniaxial anisotropy, $K_{\mathrm{u}}$, can be determined by the anisotropy field, $H_{\mathrm{k}}$, in which it is individually represented in Figures $8(\mathrm{a})$ and (b). In addition, magnetic saturation polarization, $J_{\mathrm{s}}$, of a certain sample is also another significant parameter to define $K_{\mathrm{u}}$, as denoted in Eq. [2]: 


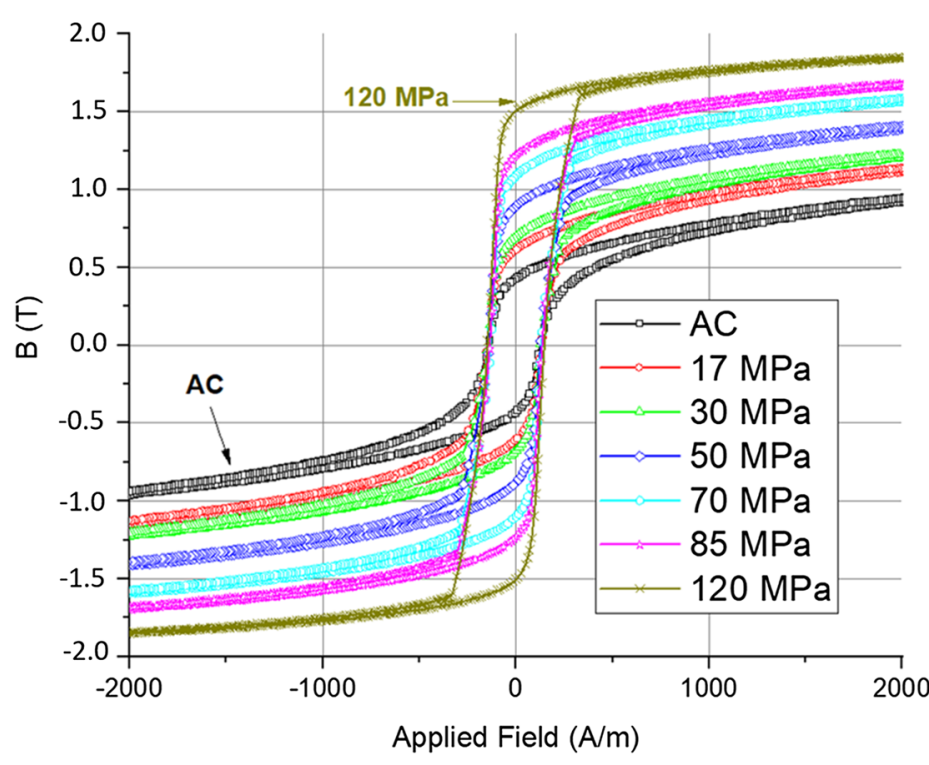

(a)

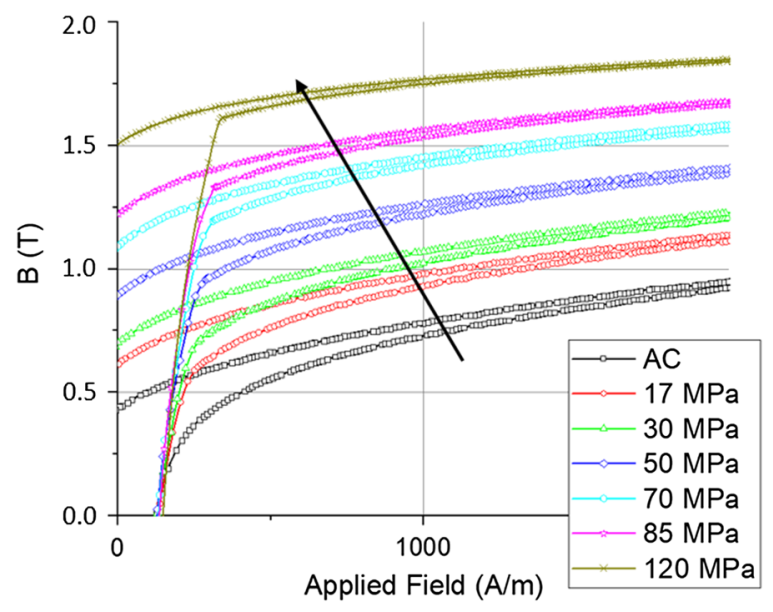

(b)

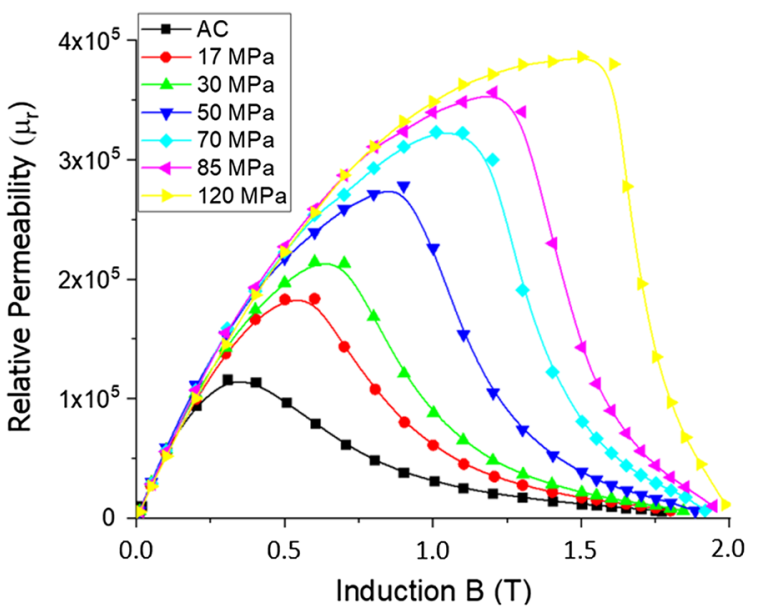

(c)

Fig. 2-Effect of tensile loading in the AC state of NC2: $(a)$ ascending full hysteresis curves, $(b)$ first quadrant of the curves, and $(c)$ variation of relative permeability values as a function of induction.
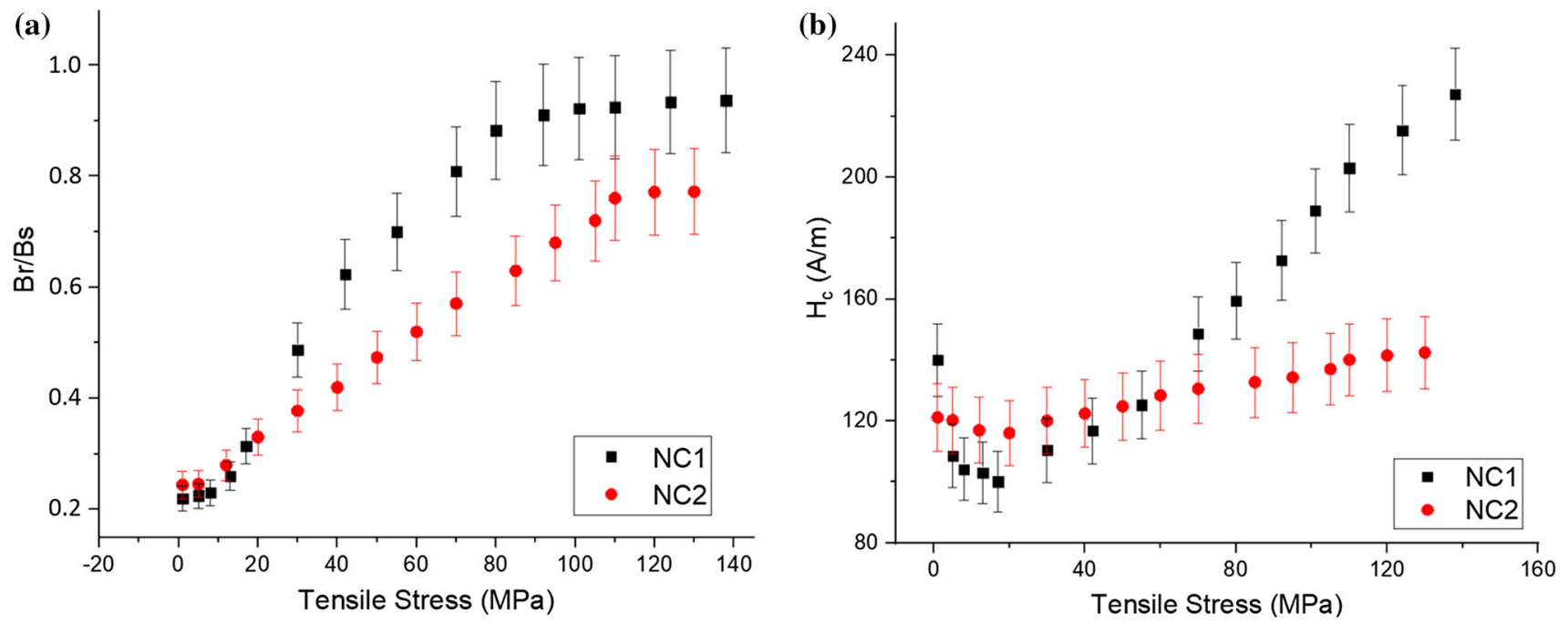

Fig. 3 - Change in magnetic properties: $(a) B_{\mathrm{r}} / B_{\mathrm{S}}$ and $(b) H_{\mathrm{c}}$ as a function of tensile stress. 


$$
K_{\mathrm{u}}=\frac{1}{2} \times H_{\mathrm{k}} \times J_{\mathrm{s}}
$$

Note that here the reverse right triangles (Figures 8(a) and (b)) were purely drawn based on the corresponding magnetization loops (Figures 7(a) and (b), major curves). Moreover, baselines of these triangles are approved as the boundary of the saturation induction (or polarization). Accordingly, uniaxial anisotropy was principally calculated considering Eq. [2] and is listed in Table I. From Figure 8 and Table I, it appears that $H_{\mathrm{k}}$ is almost ten times higher with respect to $H_{\mathrm{c}}$ in the cases of annealing without stress. However, in the state of stress annealing, NC2 indicates a peculiarly different

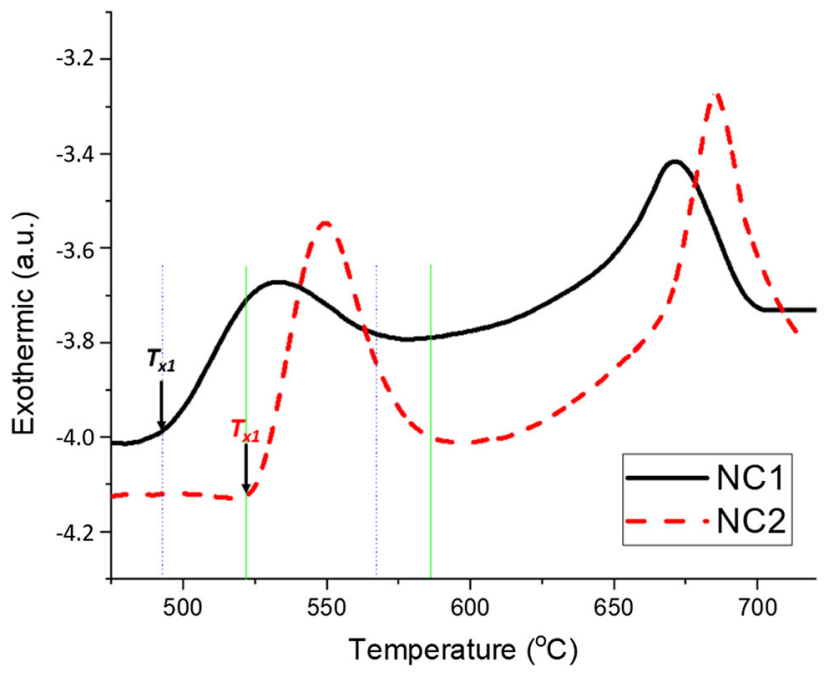

Fig. 4-Typical DSC curves for both compositions showing exothermic peaks for primary and secondary crystallization with a heating rate of $50{ }^{\circ} \mathrm{C} / \mathrm{min}$.

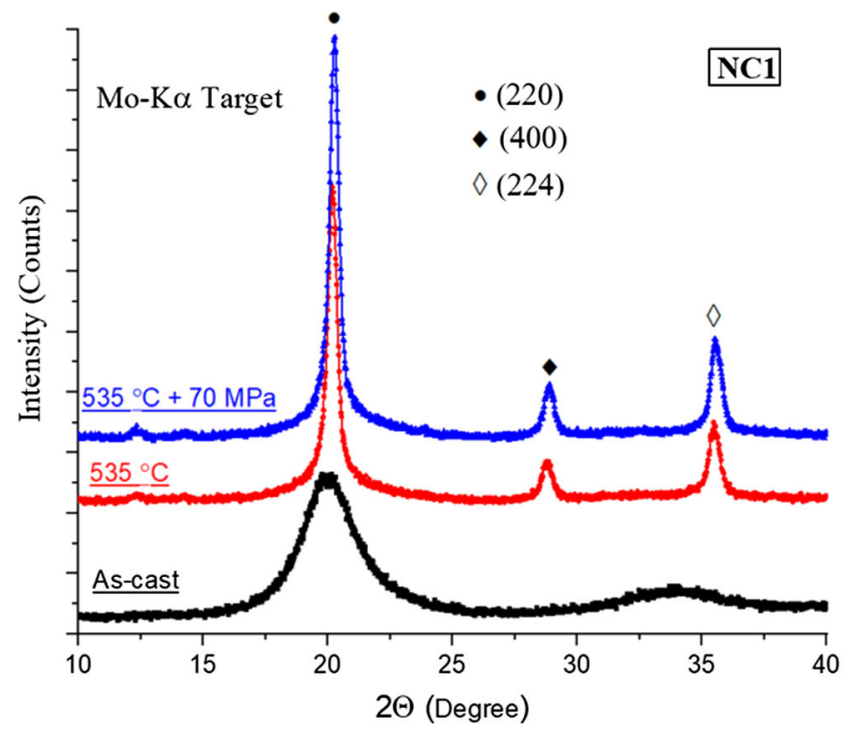

(a) reaction in terms of the ratio of $H_{\mathrm{k}} / H_{\mathrm{c}}$, i.e., $H_{\mathrm{c}}$ is quite small regarding $H_{\mathrm{k}}$ (almost 25 times). In this sense, it is expected that the permeability of the stress-annealed NC2 sample would be higher than that of others. It was determined that a slight compositional difference between $\mathrm{NC} 1$ and $\mathrm{NC} 2$ leads to a slight gradient in the value of $K_{\mathrm{u}}$. The calculated $K_{\mathrm{u}}$ in NC soft material not only represents the local contributions from the crystalline phase, but also the amorphous phase should be also considered. ${ }^{[34]}$

Note that in Figure 8 the saturation magnetic polarization was enhanced $>2000 \mathrm{~A} / \mathrm{m}$ (not shown). The difference between $\mathrm{NC} 1$ and $\mathrm{NC} 2$ in terms of $K_{\mathrm{u}}$ values refers to the area of the right rectangles.

Additionally, the volume fraction of the crystalline phase resulting from the bcc grain existence was also taken into account to ensure the overall value of $K_{\mathrm{u}}$. Since $K_{\mathrm{u}}$ depends directly on the local saturation magnetostriction, $\lambda_{\mathrm{s}}^{\text {bcc }}$, and stress annealing, $\sigma$, it became possible for nominal values of $\lambda_{\mathrm{s}}^{\mathrm{bcc}}$ to be dominant in the applied tensile stress as presented by:

$$
K_{\mathrm{u}}=-\frac{3}{2} \times \lambda_{\mathrm{s}}^{\mathrm{bcc}} \times \sigma .
$$

Thus, the optimum conditions for increasing of $\sigma$ and decreasing of $\lambda_{\mathrm{s}}^{\text {bcc }}$ may allow keeping $\lambda_{\mathrm{s}}^{\text {bcc }}$ near zero (with a minus sign). As uniaxial anisotropies can control the softness of magnetic properties in NC Fe-based alloys, which have grain sizes $<15 \mathrm{~nm},{ }^{[35]}$ optimization of overall magnetic properties for $\mathrm{NC1}$ and $\mathrm{NC} 2$ was individually enhanced at $70 \mathrm{MPa}+535^{\circ} \mathrm{C}$ and $120 \mathrm{MPa}+555^{\circ} \mathrm{C}$, respectively. Here, the most remarkable case assured the optimum circumstances, which indicate a well-ordered easy plane perpendicular to the direction of the stress axis. This case was broadly

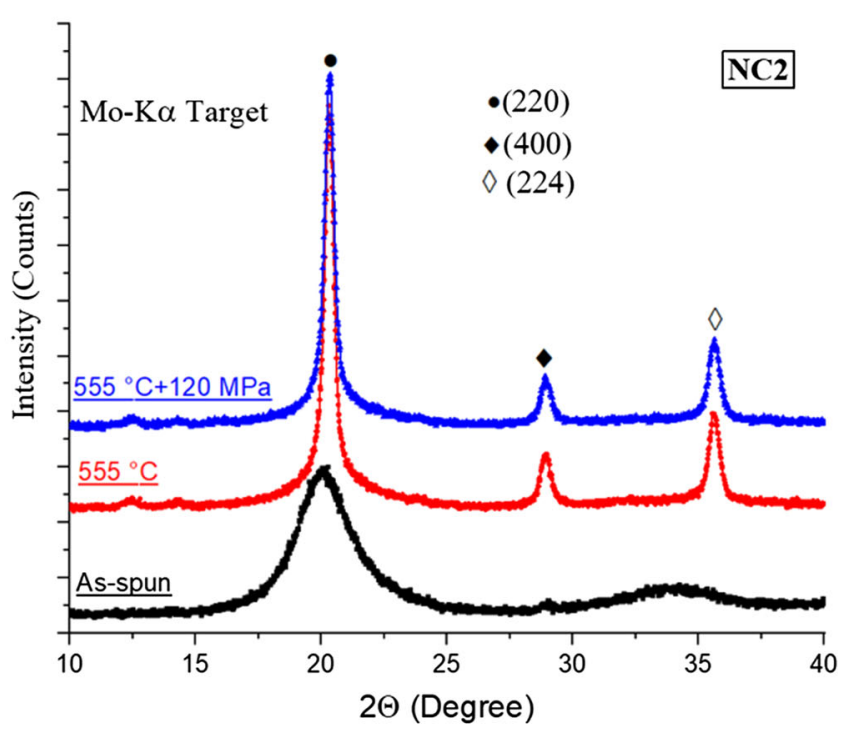

(b)

Fig. 5-X-ray diffraction patterns of the ribbons: (a) comparison conditions of $\mathrm{NC} 1$ ribbons in the $\mathrm{AC}$ state, $535{ }^{\circ} \mathrm{C}$ and $535{ }^{\circ} \mathrm{C}+70 \mathrm{MPa}$ and (b) comparison conditions of NC2 ribbons in the AC state, $555^{\circ} \mathrm{C}$ and $555{ }^{\circ} \mathrm{C}+120 \mathrm{MPa}$. 


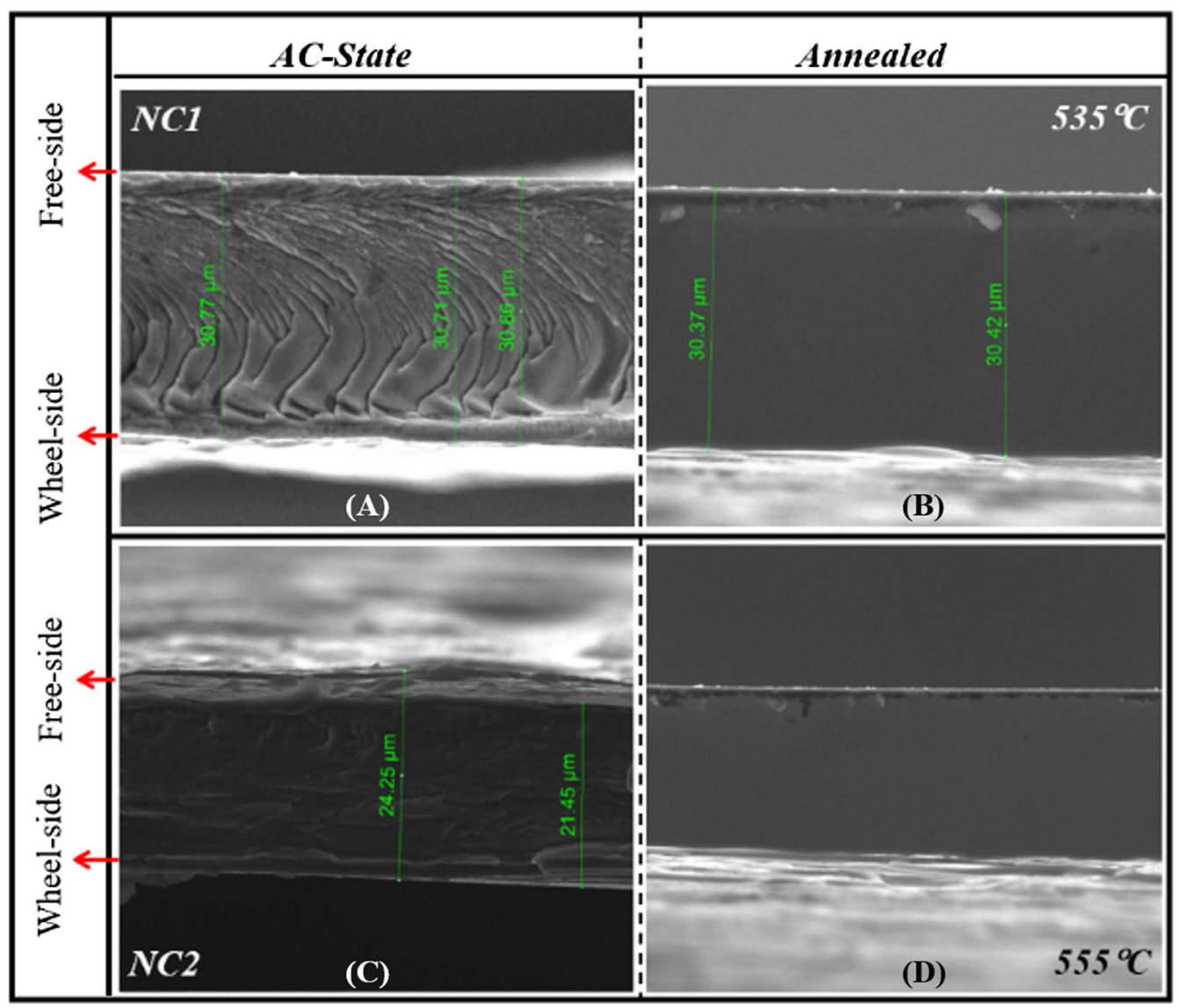

Fig. 6- SEM images of $\mathrm{NC} 1$ in the AC state $(a)$ and annealed at $535^{\circ} \mathrm{C}(b)$ and of $\mathrm{NC} 2$ in the AC state $(c)$ and annealed at $555{ }^{\circ} \mathrm{C}(d)$.

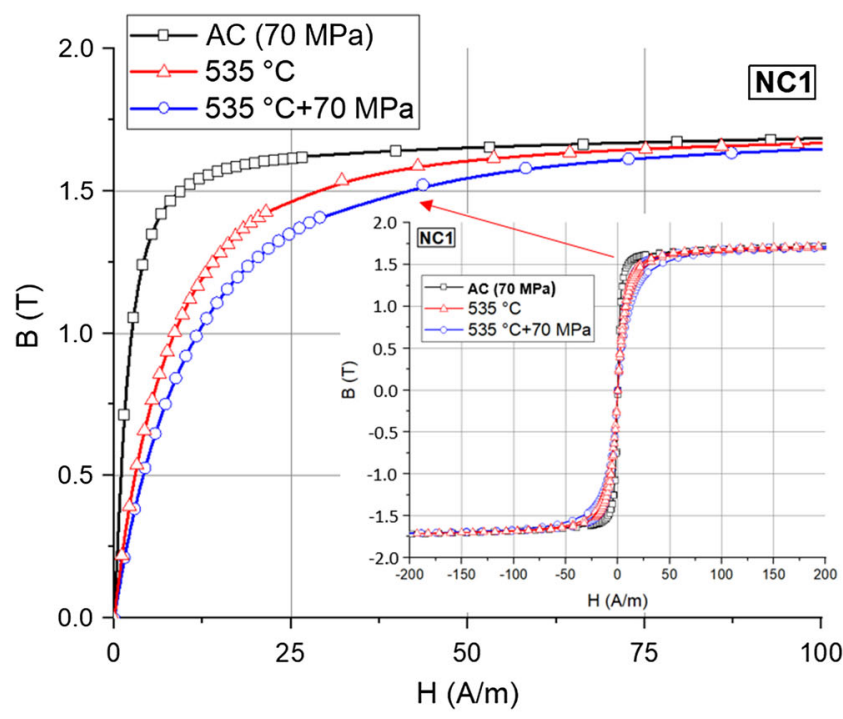

(a)

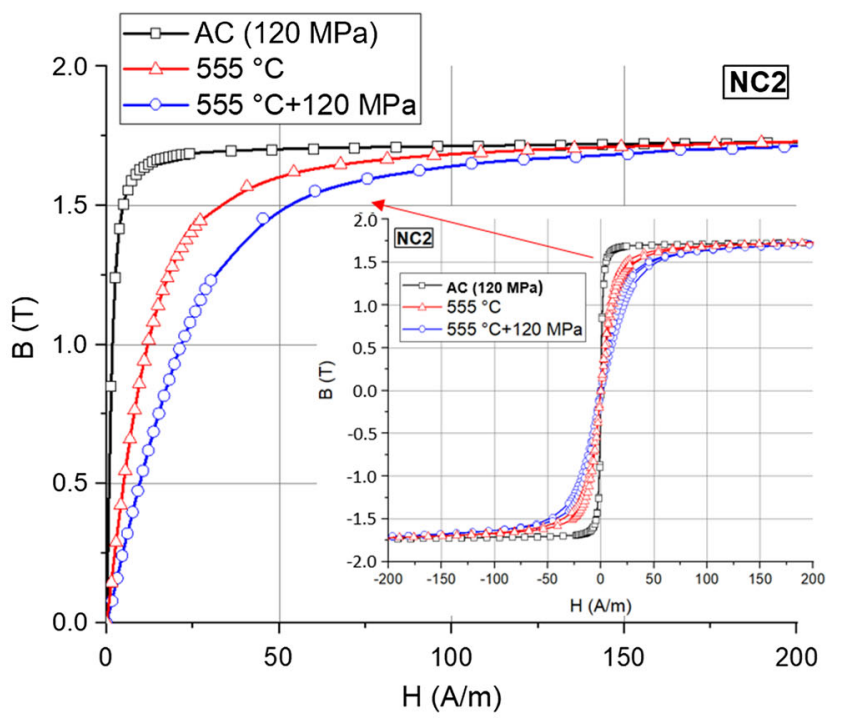

(b)

Fig. 7-Hysteresis curves of the samples with stress loading, annealed and stress annealed before and after certain annealing and stress annealing implementations for $\mathrm{NC} 1(a)$ and $\mathrm{NC} 2(b)$.

investigated by Herzer et al. ${ }^{[36]}$ where the inverse linear relation between $\sigma$ and $\lambda_{\mathrm{s}}$ was defined as the corresponding behavior of NC material.
In this study, an attempt was made to indicate the change of pct $K_{\mathrm{u}}$ upon elastic deformation by an applied tensile stress, and the value of pct $H_{\mathrm{c}}$ was determined. 


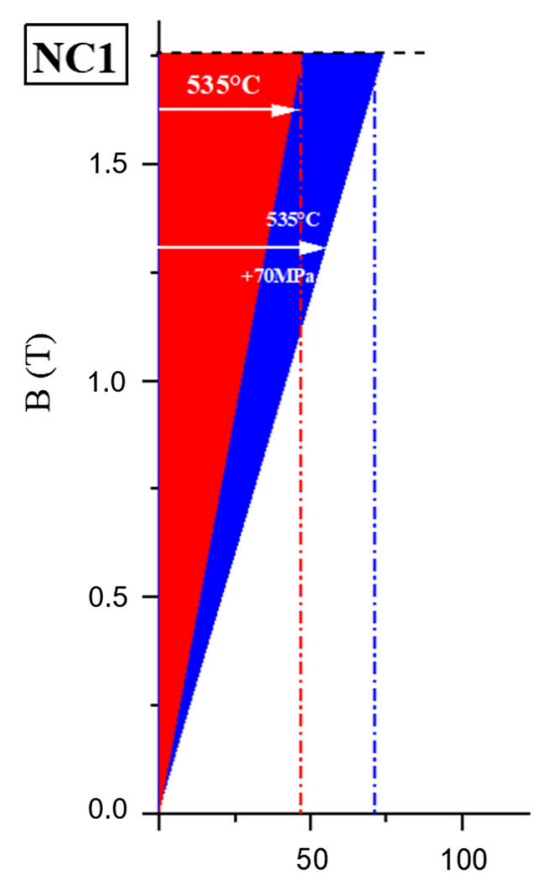

Magnetic Field Strength, $\mathrm{H}(\mathrm{A} / \mathrm{m})$

(a)

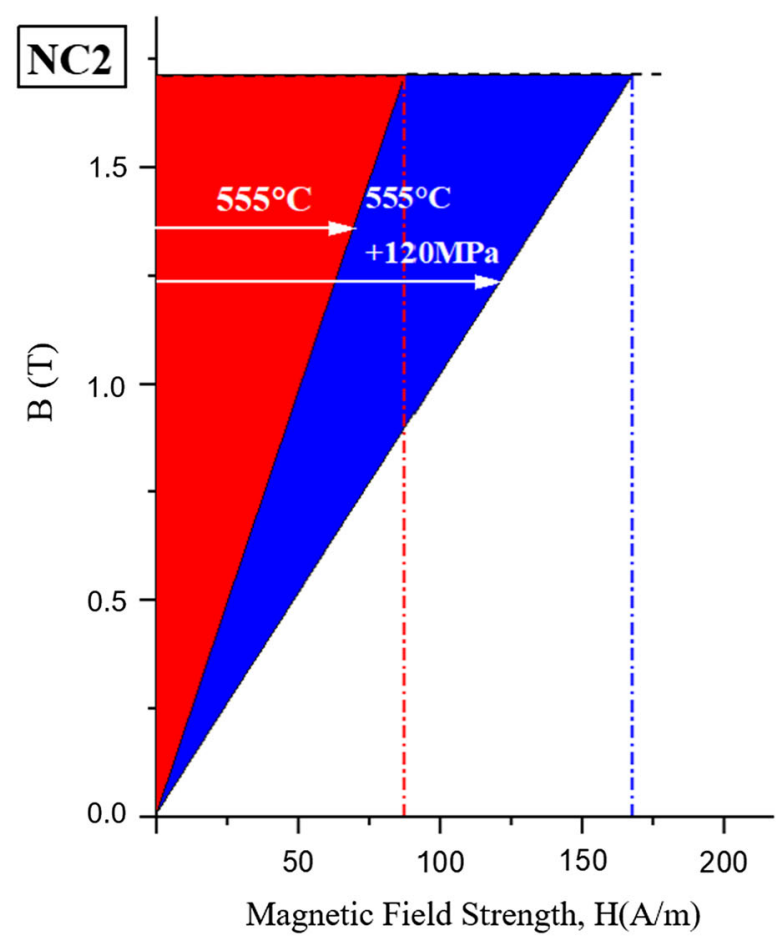

(b)

Fig. 8-The filled region to determine $K_{\mathrm{u}}$ values from initial magnetization curves of $\mathrm{NC1}(a)$ and NC2 $(b)$.

Dependently, Figure 9 is given to ensure the dynamic effect of the stress annealing to the value of $K_{\mathrm{u}}$. Therefore, $70 \mathrm{MPa}$ for $\mathrm{NC1}$ and $120 \mathrm{MPa}$ for $\mathrm{NC} 2$ were approved as excellent requirements for stress annealing conditions. Figure 10 clearly shows that the induced anisotropies as a result of different annealing temperatures led to the rise of the $H_{\mathrm{c}}$ values under the influence of fixed tensile stresses. Even though increment trends (incline) of both specimens are found similar here, the $H_{\mathrm{c}}$ value of $\mathrm{NC} 1$ is expectedly lower than that of NC2. ${ }^{[34]}$ It can be interpreted that this may have nothing to do with the stress annealing conditions; instead, it may be mostly due to their compositional difference.

Nonetheless, the present magnetic properties were found in correlation with XRD analyses. The intensity peak of (220) peak is dominant and stronger than that of (400) and (224) for both specimens. Expectedly, a broad peak is caused by the amorphous matrix in the base. The (220) reflection found at $2 \theta \approx 21 \mathrm{deg}$ is related to the crystalline $\alpha$-Fe phase where the intensity of the peaks was progressively increased and narrowed by heat and mechanical treatments. Such physical variations of the diffraction peaks mean the shrinkage of crystal grain size, which can be easily calculated by the following Scherrer formula:

$$
D=\frac{k \lambda}{\beta \cos \theta},
$$

where $D$ denotes the average crystalline size, $\beta$ is the line broadening in the radians that is known as the FWHM, $\theta$ is the Bragg angle, and $\lambda$ represents the $\mathrm{X}$-ray wavelength (for the Mo K $\alpha$ target).

In addition, in Figure 11, the mean grain size calculated with Eq. [4] and the $H_{\mathrm{c}}$ values determined from the quasi-static hysteresis curves in Figure 7 were compared for both ribbon compositions. Here, the entire annealing temperatures for $\mathrm{NC} 1$ and $\mathrm{NC} 2$ were characterized under tensile stresses at 70 and $120 \mathrm{MPa}$, respectively. The main purpose exemplifies the magnetic capability such as mean grain size and $H_{\mathrm{c}}$ as a function of the increment of annealing temperatures, which were mainly determined from DSC data. It is well established that small grain size and random orientation of $\mathrm{NC}$ grains as well as lower $H_{\mathrm{c}}$ values are the indicators of excellent soft magnetic properties. The capability of magnetic softness is mainly attributed to the shrinkage of the grain size. ${ }^{[37]}$

Here, the dependence of $H_{\mathrm{c}}$ and mean grain size on the annealing temperature is found remarkably optimum even under the influence of the moderate stress force. Meanwhile, contrary to the yielded remanence ratio $\left(B_{\mathrm{r}} / B_{\mathrm{S}}\right)$ in the specimen exposed to tensile stress without heat treatment (Figure 3(a)), it was significantly reduced in the case of stress annealing. This is obvious evidence of smaller grain size as well. ${ }^{[35]}$

In the developed random anisotropy model, Herzer ${ }^{[38]}$ emphasizes the optimum NC state where the anisotropy constant, scaled with $D^{6}$, resulted in a decrease in the grain size of about $5 \mathrm{~nm}$. In our case, acquired empirical data regarding grain sizes were found in a good accordance with the theoretical values ${ }^{[39]}$ considering the relation of $H_{\mathrm{c}} \sim D^{6}$ as illustrated in Table II. 
Table I. Values of Coercivity $\left(H_{\mathrm{c}}\right)$, Saturation Polarization $\left(J_{\mathrm{s}}\right)$, Anisotropy Field $\left(H_{\mathrm{k}}\right)$, and Uniaxial Anisotropy $\left(K_{\mathrm{u}}\right)$ for Annealing and Stress Annealing Conditions of Both Ribbon Compositions

\begin{tabular}{llcccc}
\hline Sample & Treatment & $H_{\mathrm{c}}(\mathrm{A} / \mathrm{m})$ & $J_{\mathrm{s}}(\mathrm{T})$ & $H_{\mathrm{k}}(\mathrm{A} / \mathrm{m})$ & 46.9 \\
NC1 & $535^{\circ} \mathrm{C}$ & 5.22 & 1.76 & 71.1 & $K_{\mathrm{u}}\left(\mathrm{J} / \mathrm{m}^{3}\right)$ \\
& $535^{\circ} \mathrm{C}+70 \mathrm{MPa}$ & 5.1 & 1.76 & 87.27 \\
$\mathrm{NC} 2$ & $555^{\circ} \mathrm{C}$ & 8.22 & 1.7 & 1.56 \\
& $555^{\circ} \mathrm{C}+120 \mathrm{MPa}$ & 6.68 & 1.7 & 167.2 & 14.69 \\
\hline
\end{tabular}

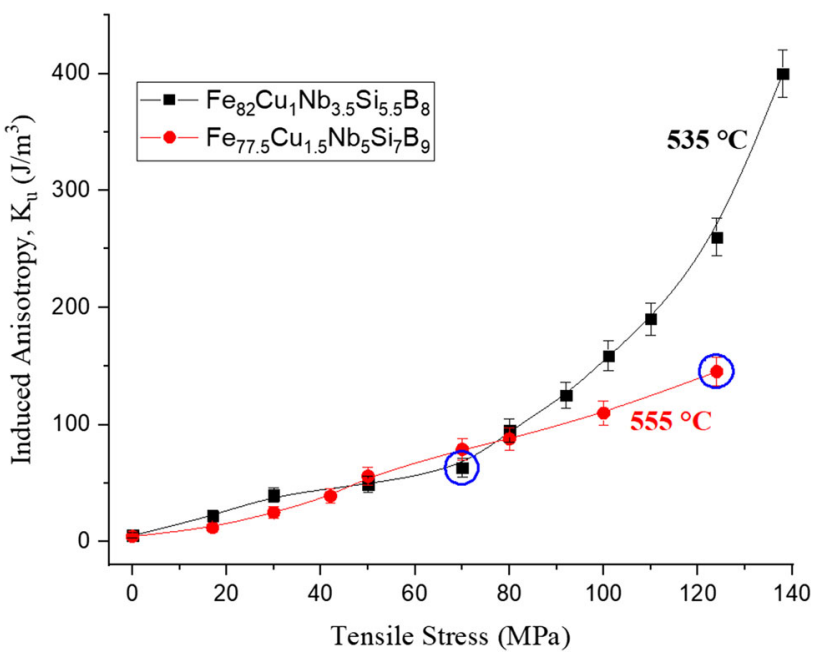

Fig. 9-Variation of induced anisotropy of $\mathrm{NC1}$ (square) at $535^{\circ} \mathrm{C}$ and of $\mathrm{NC} 2$ (circle) at $555^{\circ} \mathrm{C}$ as a function of tensile loading.

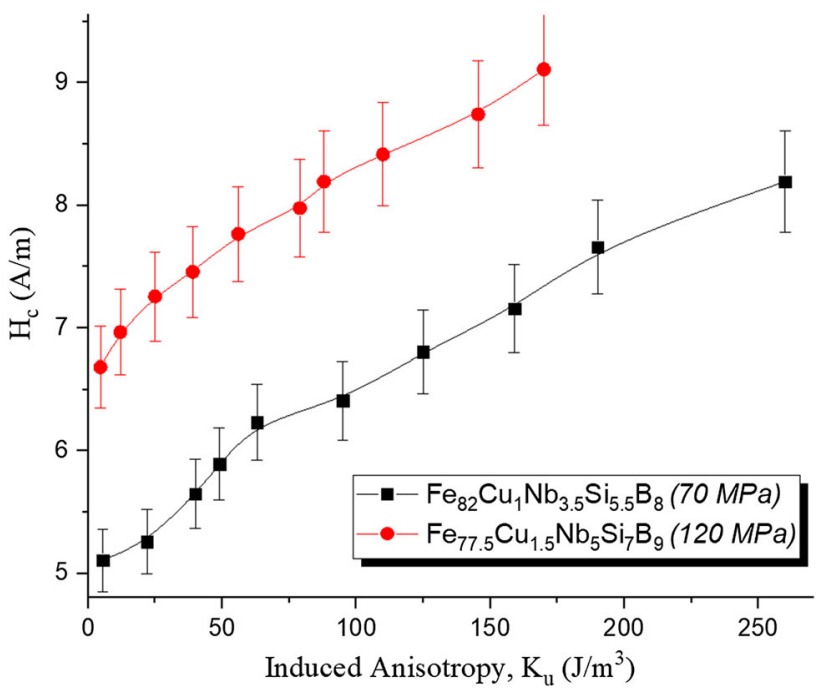

Fig. 10-Variation of coercivity values of $\mathrm{NC1}$ (square) at an actual tensile loading of $70 \mathrm{MPa}$ and of NC2 (circle) during tensile loading of $120 \mathrm{MPa}$ as a function of induced anisotropy.

Deviations of the grain size values yielded from XRD data and the theoretical values were also found negligible $(\sim 3$ pct for $\mathrm{NC1}$ and $\sim 6$ pct for $\mathrm{NC} 2)$. Accordingly, decreasing $H_{\mathrm{c}}$ values, as well as grain sizes, allow interpreting that the conditions of stress annealing achieved pull down saturation magnetostriction to the optimum state. ${ }^{[40,41]}$
As a matter fact, in the ribbons with high Fe content, they are expected to form relatively large grains $(\sim 15$ to $25 \mathrm{~nm}$ ) because of their crystalline structure. However, both XRD and magnetic (via $\mathrm{M}-\mathrm{H}$ and $\mathrm{B}-\mathrm{H}$ ) analyses indicated that stress annealing under the certain circumstances $\left(70 \mathrm{MPa}+535^{\circ} \mathrm{C}\right.$ and $\left.120 \mathrm{MPa}+555^{\circ} \mathrm{C}\right)$ led to irreversible deformations throughout the amorphous matrix and also caused the formation of less boride structure. It is believed that such conditions in the ribbons with relatively less $\mathrm{Fe}$ content enable improving ultrafine grain structures, e.g., $<1 \mathrm{~nm}$.

\section{Magneto-optical Kerr Imaging}

The presentation of XRD, EDS, SEM, and TEM would be helpful to ensure the microstructural evaluation under the influence of external treatments. Alternatively, Kerr imaging can be used to estimate the in-plane crystalline-texture considering domain orientation as a function of the tensile force and applied magnetic field axis. Residual anisotropies are mostly preferred to characterize the easy direction where domains become visible as long as they are perpendicular to the axis of the magneto-optical sensitivity. ${ }^{[42]}$ In addition, the magnetic domain structure can be improved by decreasing the thickness of the $\mathrm{NC}$ ribbon. ${ }^{[43]}$ Accordingly, the thickness of $\mathrm{NC} 2$ $(\sim 20 \mu \mathrm{m})$ was very convenient for displaying the domain refinement under the influence of the tensile force. In Figure 12, stress-dominated domain patterns in the AC state are presented with two different sensitivity axes: transversal and longitudinal. Nevertheless, it is hard to determine the orientation of the easy axis with certainty, since the stress patterns as well as Kerr resolution are not adequate to distinguish them in a selected zone. To be more precise, a mild tensile stress of $17 \mathrm{MPa}$ was implemented throughout the long axis of the ribbon. Therefore, it was found sufficient to overcome stress domination. Thus, the difference between sensitivity axes was explicitly revealed after the tensile force was switched on (bottom spots). It is also noted that each spot herein demonstrates the same region.

Regardless of the effect of the magnetic field, it is clear that the applied tensile stress somewhat vitiates the residual stress patterns, which can appear to be superimposed on the wide domain patterns where curved domains are along the principal direction. In the case of non-tensile loading, stress-dominated patterns sustained their existence, while it was quite difficult to observe planar domains surrounded by stress patterns as 


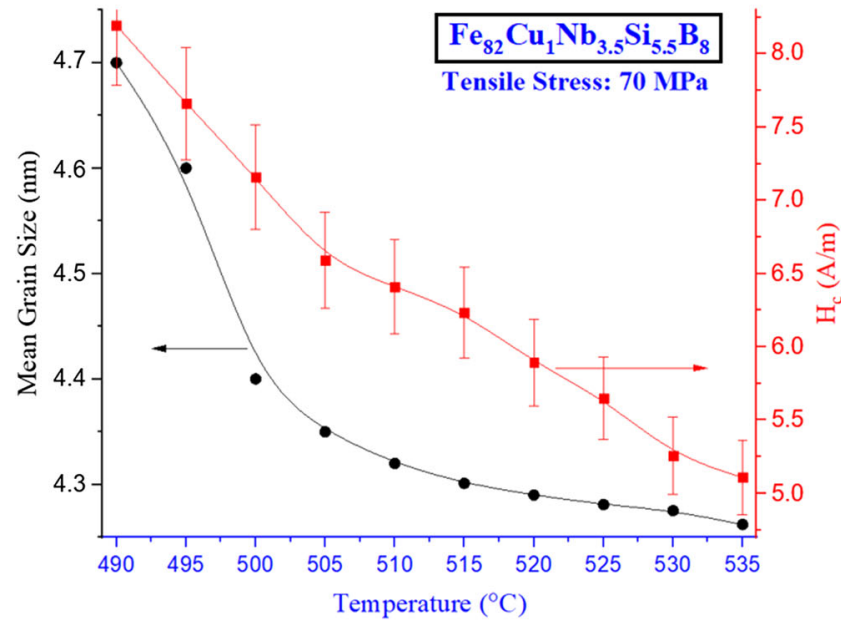

(a)

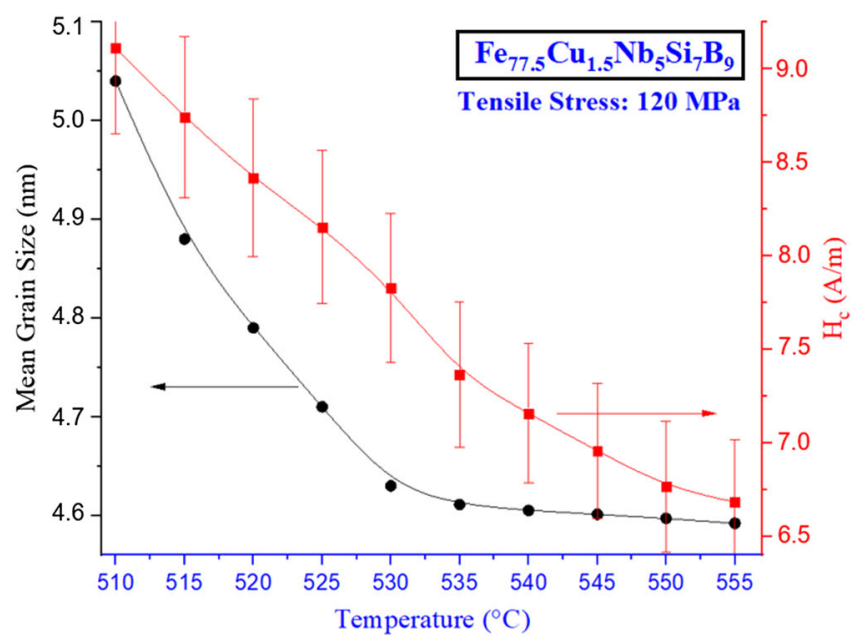

(b)

Fig. 11-Average grain size and coercivity evaluation depending on the change on stress annealing temperatures: $(a) 490{ }^{\circ} \mathrm{C}$ to $535{ }^{\circ} \mathrm{C}$ at the constant tensile stress of $70 \mathrm{MPa}$ for the ribbon $\mathrm{NC} 1$ and $(b) 510{ }^{\circ} \mathrm{C}$ to $555^{\circ} \mathrm{C}$ at the constant tensile stress of $120 \mathrm{MPa}$ for the ribbon $\mathrm{NC}$.

Table II. Deviation Between Experimental (XRD Data Yields) and Theoretical (Pct $H_{\mathrm{c}} \sim D^{6}$ ) Grain Size Values

\begin{tabular}{lccc}
\hline Sample (Treatments) & $\begin{array}{c}\text { XRD Data Yields (by Scherrer } \\
\text { Equation) (nm) }\end{array}$ & $\begin{array}{c}H_{\mathrm{c}} \sim D^{6}(\text { Theoretical) } \\
(\mathrm{nm})\end{array}$ & $\begin{array}{c}\text { Deviation } \\
(\text { Pct })\end{array}$ \\
\hline $\mathrm{Fe}_{82} \mathrm{Cu}_{1} \mathrm{Nb}_{3.5} \mathrm{Si}_{5.5} \mathrm{~B}_{8}\left(70 \mathrm{MPa}, 535^{\circ} \mathrm{C}\right)$ & 4.262 & 4.15 & $\sim 3$ \\
$\mathrm{Fe}_{77.5} \mathrm{Cu}_{1.5} \mathrm{Nb}_{5} \mathrm{Si}_{7} \mathrm{~B}_{9}\left(120 \mathrm{MPa}, 555^{\circ} \mathrm{C}\right)$ & 4.592 & 4.34 & $\sim 6$ \\
\hline
\end{tabular}

represented in the sequential images of Figure 13(a). Therefore, the annihilation of certain stress patterns was not permanently enhanced without implementation of tensile force and/or heat treatment. In the second part of Figure 13(b), however, tensile force without a magnetic field was activated until the physical integrity of the ribbon was lost (after $120 \mathrm{MPa}$ ). Expectedly, a strong enough tensile force led first to the formation of wide-curved domains along the planar tensile axis as the prevailing magnetization process. Then, the number of patterns gradually increased depending on the actual tensile force. Consequently, the domain width became smaller at lower $K_{\mathrm{u}}$, that means that lower $K_{\mathrm{u}}$ leads to more walls. However, there were no strong changes in the curvy state of the wall. As a matter of fact, ribbons in the AC state have principally wide domains separated by curved walls ${ }^{[4]}$ depending on the residual anisotropies and the sign of the magnetostriction constant. Additionally, external applied tensile force makes a uniform domain arrangement with less curved walls possible. This case may also lead to inhomogeneous magnetization in which a fluctuating magnetization direction appears due to the existence of the average random magnetocrystalline anisotropy. ${ }^{[45]}$

Regular wide domains are essential for $\mathrm{NC} \mathrm{FeCuNb}$ $\mathrm{SiB}$ ribbons with uniaxial induced anisotropy. To achieve the flat 180 deg wall structure, a heat treatment around the primary crystallization temperatures should be applied since this usually leads to relaxation of $>95$ pct of the stress. ${ }^{[28]}$

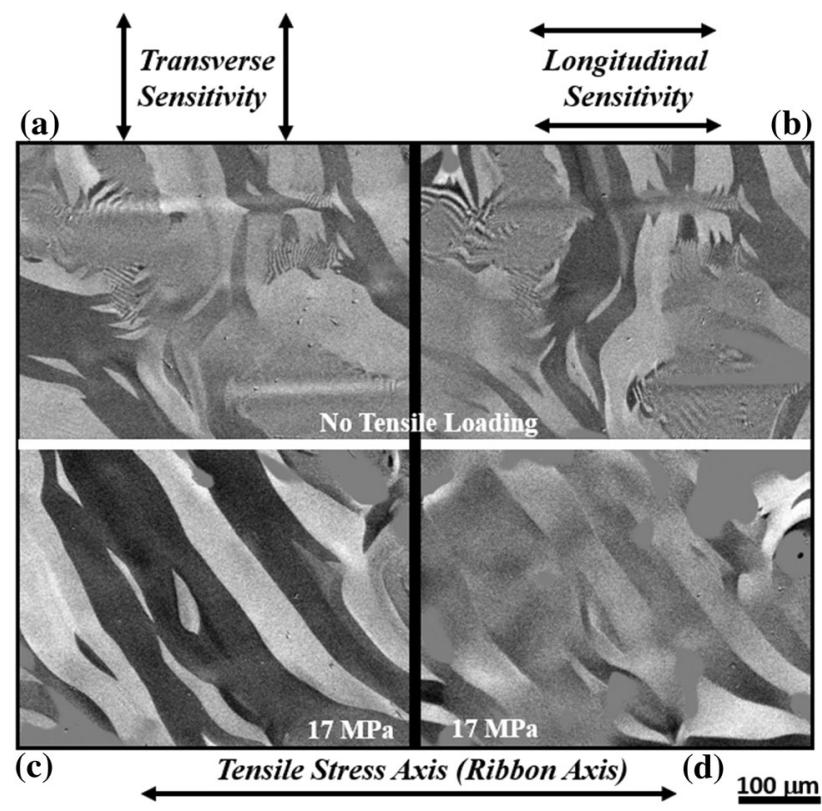

Fig. 12-The domain images belonging to NC2 specimens were observed using both transverse Kerr sensitivity without $(a)$ and with tensile loading of $17 \mathrm{MPa}(c)$ and longitudinal sensitivity without $(b)$ and with tensile loading of $17 \mathrm{MPa}(d)$.

Furthermore, based on the obtained satisfied enhancement in magnetic properties, tensile force was sequentially applied. After each implementation, microstructural evaluation could be observed by Kerr 


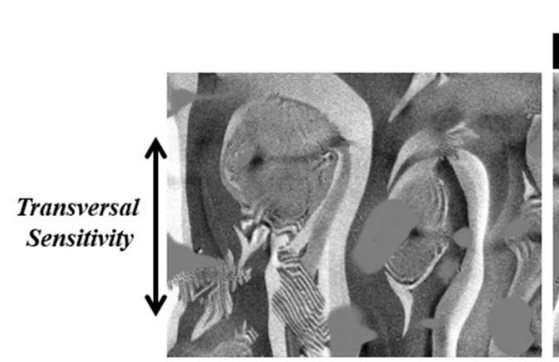

Demagnetized state

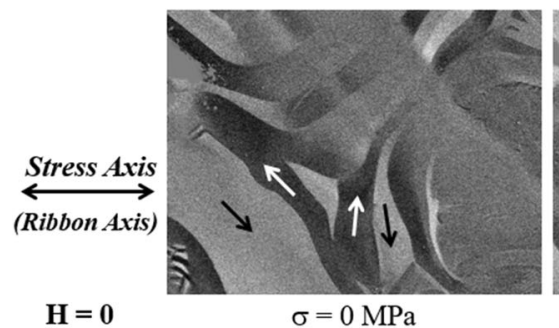

$\mathbf{H}=\mathbf{0}$

$\sigma=0 \mathrm{MPa}$

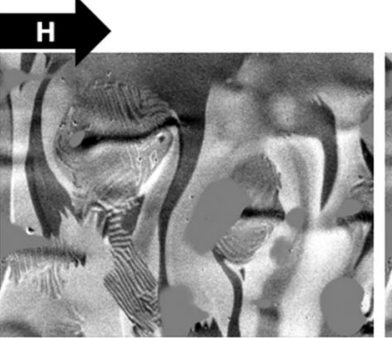

$\mathrm{H}=10 \mathrm{~A} / \mathrm{m}$

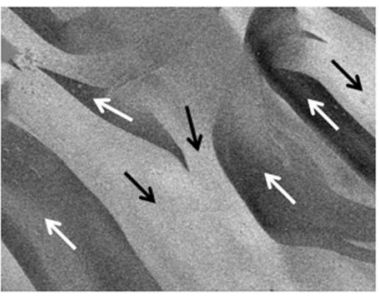

$\sigma=30 \mathrm{MPa}$

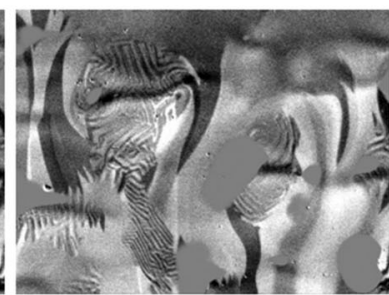

$\mathrm{H}=100 \mathrm{~A} / \mathrm{m}$

(a)

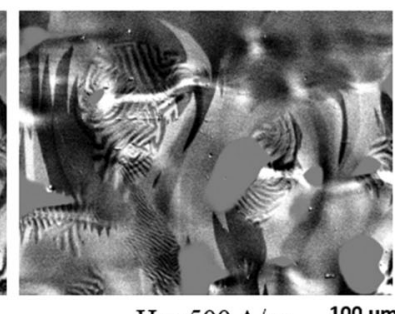

$\mathrm{H}=500 \mathrm{~A} / \mathrm{m}$

$100 \mu \mathrm{m}$

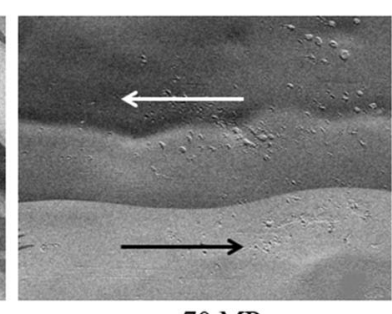

$\sigma=70 \mathrm{MPa}$

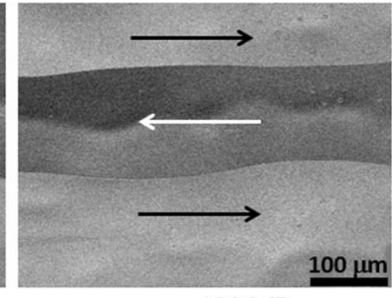

$\sigma=120 \mathrm{MPa}$

(b)

Fig. 13-Kerr images: (a) applied field up to $0.5 \mathrm{kA} / \mathrm{m}$ failed for the annihilation of stress patterns and $(b)$ tensile loading up to $120 \mathrm{MPa}$ lack of magnetic field caused wall curving.

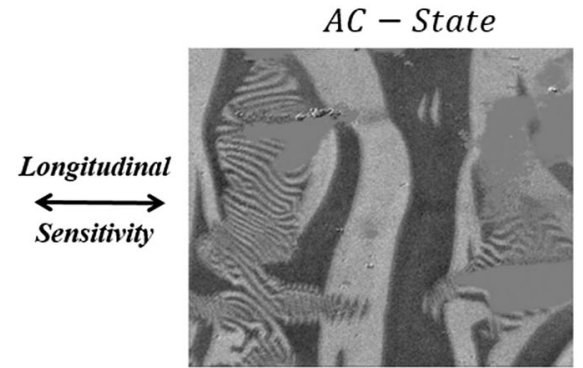

(a) $\quad H=0$

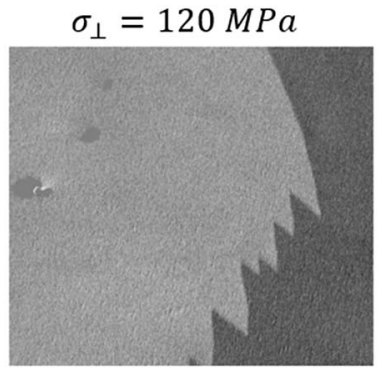

(b) $H=0$

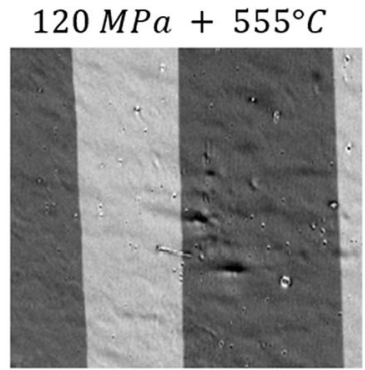

(c) $H=0$

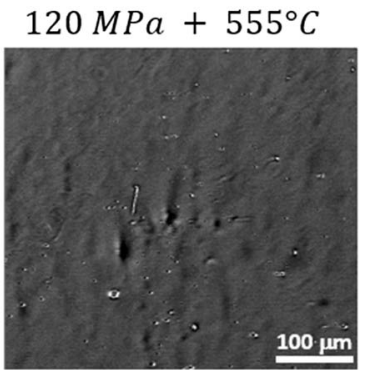

(d) $H_{\perp}=160 \mathrm{~A} / \mathrm{m}=H_{k}$

Fig. 14-The domain evaluation steps in the AC state $(a)$ in the presence of tensile stress of $120 \mathrm{MPa}(b)$, under the influence of stress annealing at $120 \mathrm{MPa}+555^{\circ} \mathrm{C}$ regardless of application of magnetic field $(c)$, and stress annealing at $120 \mathrm{MPa}+555^{\circ} \mathrm{C}$ under magnetic field implementation $(d)$.

microscopy, as shown in Figure 14. Here, again, the stress domination appears with a curved domain in the $\mathrm{AC}$ state. The tensile force of $120 \mathrm{MPa}$ and then heat treatment at $555{ }^{\circ} \mathrm{C}$ enable obtaining prominent slablike domains without any stress pattern and field contribution. The data from Figure 7(b) confirm that in the state of $120 \mathrm{MPa}+555^{\circ} \mathrm{C}$, the ribbon is well-saturated under the influence of the determined anisotropy field, $H_{\mathrm{k}}$, of $160 \mathrm{~A} / \mathrm{m}$.

\section{CONCLUSIONS}

Fe-based $\mathrm{NC} 1$ and $\mathrm{NC} 2$ amorphous precursors were produced in thicknesses of around 30 and $20 \mu \mathrm{m}$, respectively. Regardless of the application of heat treatment, only tensile force was implemented on the ribbon in the AC state to make a connection between the amorphous phase and nanocrystallization requirements. Depending on the yielded magnetic properties such as $H_{\mathrm{c}}, B_{\mathrm{r}} / B_{\mathrm{s}}$ and $\mu_{\mathrm{r}}$ quasi-static hysteresis loops of tensile stressed AC ribbons and treatment conditions were successfully determined. In addition, exothermic crystallization temperatures were found for the specimen of $\mathrm{NC} 1$ and $\mathrm{NC} 2$ where the region was designated between $T_{\mathrm{x} 1}$ and the first peak of primary crystallization. Accordingly, standard analyses were properly performed to present certain NC soft magnetic materials. Afterward, optimum conditions to obtain superior magnetic capability were sought. Some of the prominent conclusions are as follows:

- Specified requirements in $\mathrm{NC} 1$ and $\mathrm{NC} 2$ were found to be $70 \mathrm{MPa}+535{ }^{\circ} \mathrm{C}$ and $120 \mathrm{MPa}+555^{\circ} \mathrm{C}$, respectively.

- Mean grain sizes were also experimentally found to be $4.26 \mathrm{~nm}(\mathrm{NC} 1)$ and $4.59 \mathrm{~nm}(\mathrm{NC} 2)$ where they were close to the nominal values described in the literature. Besides, the corresponding $H_{\mathrm{c}}$ indicates 
minor deviations as small as 3 to 6 pct from the theoretical values $\left(H_{\mathrm{c}} \sim D^{6}\right)$.

- Expectedly, uniaxial anisotropy $\left(K_{\mathrm{u}}\right)$ values after annealing were found relatively small in the range of 41 to $75 \mathrm{~J} / \mathrm{m}^{3}$. Despite this, the increment ratio after implementations of tensile force and annealing was measured at around 55 pct for $\mathrm{NC1}$ and 92 pct for NC2. The main reason for this probably depends on the tensile force applied to the NC2, which is higher $(\sim 70 \mathrm{pct})$ than that of $\mathrm{NC1}$.

- Magneto-optical Kerr imaging indicated that tensile force of $120 \mathrm{MPa}$ caused reversible deformations resulting in a curvy state of the domain walls in the AC state. However, this unstable state was properly annihilated applying tensile force together with favorable heat treatment.

- Eventually, acquired transverse induced anisotropy led to the formation of a uniform domain arrangement perpendicular to the ribbon axis. Thus, the specimen was well saturated in the anisotropy field of $160 \mathrm{~A} / \mathrm{m}$, which means good correlation with the designated magnetic properties.

\section{ACKNOWLEDGMENTS}

This work was supported by the Research Fund of Yalova University with Project Number of 2017/AP/ 139. The author especially thanks IFW Dresden for providing the possibility to perform Kerr imaging and Rudolf Schäfer for fruitful scientific contributions.

\section{REFERENCES}

1. O. Gutfleisch, M.A. Willard, E. Brück, C.H. Chen, S.G. Sankar, and J.P. Liu: Adv. Mater., 2011, vol. 23, pp. 821-42.

2. L. Xie, T. Liu, A. He, Q. Li, Z. Gao, A. Wang, C. Chang, X. Wang, and C.T. Liu: J. Mater. Sci., 2018, vol. 53, pp. 1437-46.

3. R. Hasegawa: J. Magn. Magn. Mater., 2000, vol. 215, pp. 240-45.

4. Y.C. Niu, X.F. Bian, W.M. Wang, S.F. Jin, G.H. Li, F.M. Chu, and W.G. Zhang: Alloys Compd, 2007, vol. 433, pp. 296-301.

5. G. Herzer: Acta Mater., 2013, vol. 61, pp. 718-34.

6. A. Makino, H. Men, T. Kubota, K. Yubuta, and A. Inoue: Mater. Trans., 2009, vol. 50, p. 204.

7. K. Takenaka, N. Nishiyama, A.D. Setyawan, P. Sharma, and A. Makino: J. Appl. Phys., 2015, vol. 117, p. 17D519.

8. L. Yue, I. Al-Omari, W. Zhang, R. Skomski, and D. Sellmyer: MRS Symp. Proc., 2013, https://doi.org/10.1557/opl.2013.1105.

9. R. Schäfer: in The Magnetic Microstructure $f$ Nanostructured Materials, J. Liu, E. Fullerton, O. Gutfleisch, and D. Sellmyer, eds., Springer, Boston, 2009, 1st ed., pp. 275-307.

10. A. Benchabi, F. Alves, R. Barrué, J. Faugières, and J. Rialland: Eur. Phys. J. Appl. Phys., 2001, vol. 15, pp. 173-76.

11. S. Flohrer, R. Schäfer, C. Polak, and G. Herzer: Acta Mater., 2005, vol. 53, pp. 2937-42.

12. S. Flohrer, R. Schäfer, J. McCord, S. Roth, L. Schultz, F. Fiorillo, W. Günther, and G. Herzer: Acta Mater., 2006, vol. 54, pp. $4693-98$.

13. M. Kuhnt, X. Xu, M. Amalraj, P.L. Kozikowski, K.G. Pradeep, T. Ohkubo, M. Marsilius, T. Strache, C. Polak, M. Ohnuma, K. Hono, and G. Herzer: Alloys Compd, 2018, vol. 766, pp. 686-93.
14. M. Ohta and Y. Yoshizawa: J. Phys. D, 2011, vol. 44, p. 064004.

15. I.A. Figueroa, I. Betancourt, G. Lara, and J.A. Verduzco: $J$. Non-Cryst. Solids, 2005, vol. 351, pp. 3075-80.

16. J. Zhang, F. Wan, Y. Li, J. Zheng, A. Wang, J. Song, M. Tian, A. He, and C. Chang: J. Magn. Magn. Mater., 2017, vol. 438, pp. 126-31.

17. H.R. Lashgari, D. Chua, S. Xie, H. Sun, M. Ferry, and S. Li: J. Non-Cryst. Solids, 2014, vol. 391, pp. 61-82.

18. M.A. Willard, M. Daniil, and K.E. Kniping: Scripta Mater., 2012, vol. 67 , pp. 554-59.

19. M. Ohnuma, K. Hono, S. Linderoth, J.S. Pedersen, Y. Yoshizawa, and H. Onodera: Acta Mater., 2000, vol. 48, pp. 4783-90.

20. G. Herzer, M. Marsilius, and C. Polak: J. Korean Phys. Soc., 2013, vol. 62 , pp. $1465-68$.

21. M. Kuhnt, M. Marsilius, T. Strache, C. Polak, and G. Herzer: Scripta Mater., 2017, vol. 130, pp. 46-48.

22. E. Lopatina, I. Soldatov, V. Budinsky, M. Marsilius, L. Schultz, G. Herzer, and R. Schäfer: Acta Mater., 2015, vol. 96, pp. 1017.

23. S. Flohrer and G. Herzer: J. Magn. Magn. Mater., 2010, vol. 322, pp. 1511-14.

24. Y. Yoshizawa, S. Oguma, and K. Yamauchi: J. Appl. Phys., 1988, vol. 64, p. 6044 .

25. R. Hilzinger: Series in Materials Science and Engineering: Novel Nanocrystalline Alloys and Magnetic Nanomaterials, 1st ed., IOP Publishing, Philadelphia, 2005, pp. 292-95.

26. A. Nosenko, T. Mika, O. Rudenko, Y. Yarmoshchuk, and V. Nosenko: Nanoscale Res. Lett., 2015, vol. 10, p. 136.

27. A. Nosenko, T. Mika, O. Semyrga, and V. Nosenko: Nanoscale Res. Lett., 2017, vol. 12, p. 299.

28. A. Hubert and R. Schäfer: Magnetic Domains, $3^{\text {rd }}$ ed., Springer, Berlin, 1998, pp. 446, 547.

29. G.J. González, N. Murillo, J.M. Blanco, J.M. González, and T. Kulik: J. Appl. Phys., 1994, vol. 76, p. 1131.

30. G. Herzer, V. Budinsky, and C. Polak: Phys. Status Solidi B, 2011, vol. 248 , pp. $2382-88$.

31. T. Gunes, R. Schäfer, and N. Derebasi: IEEE Trans. Magn., 2018, vol. 99, pp. 1-8.

32. S.D. Kaloshkin, B.V. Jalnin, E.V. Kaevitser, and J. Xu: Properties and Applications of Nanocrystalline Alloys from Amorphous Precursors, NATO Science Series, $1^{\text {st }}$ ed., Springer, Dordrecht, 2005, pp. 99-110.

33. J. Zhou, L. Meng, F. Yang, G. Ma, and L. Chen: J. Mater. Sci. Mater. Electron., 2017, vol. 28, pp. 6829-36.

34. R. Parsons, J.S. Garitaonandia, T. Yanai, K. Onodera, H. Kishimoto, A. Kato, and K. Suzuki: J. Alloys Compd, 2017, vol. 695, pp. 3156-62.

35. G. Herzer: J. Magn. Magn. Mater., 2005, vol. 294, pp. 99106.

36. G. Herzer, S. Flohrer, and C. Polak: IEEE Trans. Magn., 2010, vol. 46, pp. 341-44.

37. K. Suzuki and G. Herzer: Scripta Mater., 2012, vol. 67, pp. 548-53.

38. G. Herzer: NATO Sci. Ser. II, 2005, vol. 184, p. 15

39. K. Suzuki, N. Ito, J.S. Garitaonandia, J.D. Cashion, and G. Herzer: J. Non-Cryst. Solids, 2008, vol. 354, pp. 5089-92.

40. A. Hernando, P. Marin, M. Vazquez, and G. Herzer: J. Magn. Magn. Mater., 1998, vols. 177-181, pp. 959-61.

41. R. Grössinger, R.S. Turtelli, V.H. Duong, Ch. Kuß, Ch. Polak, and G. Herzer: Mater. Sci. Forum, 1999, vol. 307, pp. 135-42.

42. R. Schäfer: Nanoscale Magnetic Materials and Applications, 1st ed., Springer, Dordrecht, 2009, pp. 277-83.

43. Z. Li, K. Yao, D. Li, X. Ni, and Z. Lu: Prog. Nat. Sci. Mater. Int., 2017, vol. 27, pp. 588-92.

44. R. Schäfer, N. Mattern, and G. Herzer: IEEE Trans. Magn., 1996, vol. 32, pp. 4809-11.

45. S. Flohrer, R. Schäfer, and G. Herzer: J. Non-Cryst. Solids, 2008, vol. 354 , pp. 5097-5100.

Publisher's Note Springer Nature remains neutral with regard to jurisdictional claims in published maps and institutional affiliations. 